\title{
ALTAS CONCENTRAÇÕES DE OXIGÊNIO FAVORECEM A CONSERVAÇÃO DE MORANGO 'OSO GRANDE'’
}

\author{
LUIS CARLOS CUNHA JUNIOR ${ }^{2}$, ANGELO PEDRO JACOMINO ${ }^{3}$, \\ MARCOS JOSE TREVISAN ${ }^{4}$, JOR̃O ALEXIO SCARPARE FILHO ${ }^{3}$
}

RESUMO - Aplicação de atmosferas com altos níveis de $\mathrm{O}_{2}$ podem manter a qualidade dos vegetais e retardar o crescimento de microrganismos. O objetivo deste trabalho foi avaliar a qualidade do morango 'Oso Grande' sob atmosfera controlada com diferentes concentrações de $\mathrm{O}_{2}$. Os morangos foram selecionados, resfriados e armazenados a $10^{\circ} \mathrm{C}$ em minicâmaras herméticas, onde foram aplicadas as distintas concentrações de $\mathrm{O}_{2}$ (1; 3; 20; 60 e 90\%), em fluxo contínuo de $150 \mathrm{~mL} \mathrm{~min}^{-1}$, durante o armazenamento (10 dias). Os frutos foram avaliados a cada 2 dias. As menores incidências de podridões foram observadas nos tratamentos com $90 \% \mathrm{O}_{2}\left(3 \%\right.$ dos frutos) e com $60 \% \mathrm{O}_{2}(6 \%$ dos frutos). Estes tratamentos proporcionaram também melhor conservação dos frutos, demonstrada pelas melhores notas de aparência. Os demais tratamentos apresentaram 16 a $20 \%$ de frutos com podridões. A atividade respiratória dos frutos armazenados sob 1 e $3 \%$ de $\mathrm{O}_{2}$ foi de 11,3 e 15,3 $\mathrm{mL} \mathrm{CO}_{2} \mathrm{~kg}^{-1} \mathrm{~h}^{-1}$, respectivamente, sendo inferior aos demais tratamentos, que não foram significativamente diferentes entre si e cujo valor médio foi de $21 \mathrm{~mL} \mathrm{CO}_{2} \mathrm{~kg}^{-1} \mathrm{~h}^{-1}$. Os teores de acetaldeído e etanol não aumentaram significativamente, durante o armazenamento. A firmeza da polpa não diferiu entre os tratamentos. Os morangos submetidos a $60 \%$ de $\mathrm{O}_{2}$ não alteraram seus teores de acidez total titulável e de ácido ascórbico durante o armazenamento, enquanto nos demais tratamentos houve decréscimo no teor de ácido ascórbico no mesmo período. As concentrações de $\mathrm{O}_{2}$ levaram a diferenças na coloração externa, em termos de luminosidade, cromaticidade e ângulo de cor; entretanto, tais diferenças foram visualmente imperceptíveis. Morangos 'Oso Grande' armazenados a $10^{\circ} \mathrm{C}$ sob atmosfera controlada com 60 e $90 \%$ de $\mathrm{O}_{2}$ mantiveram suas características de aparência e tiveram menor índice de doença, quando comparados com os demais tratamentos.

Termos para indexação: Atmosfera Controlada, Controle do Oxigênio, Pós-Colheita, Fragaria x ananassa.

\section{HIGH OXYGEN CONCENTRATIONS BETTER PRESERVE 'OSO GRANDE' STRAWBERRY}

\begin{abstract}
Atmospheres with high levels of $\mathrm{O}_{2}$ can maintain the quality of vegetables and reduce microbial growth. The aim of this study was to evaluate the quality of 'Oso Grande' strawberry under controlled atmosphere with various $\mathrm{O}_{2}$ concentrations. Strawberries were selected, air-cooled and stored at $10^{\circ} \mathrm{C}$ in hermetic mini chambers where $\mathrm{O}_{2}$ concentrations $(1,3,20,60$ and $90 \%)$ were applied continuously at 150

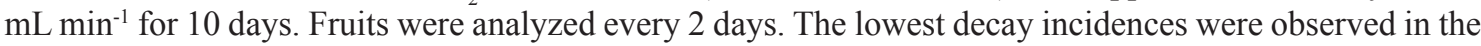
treatments with $90 \%$ of $\mathrm{O}_{2}$ (3\% of fruits) and $60 \%$ of $\mathrm{O}_{2}(6 \%$ of fruits). Fruit from these treatments also had higher appearance ratings, which indicates preservation of fruit quality. Other treatments exhibited 16 to $20 \%$ of decay. The fruit respiratory rate stored at 1 and $3 \%$ of $\mathrm{O}_{2}$ concentration was 11.3 and $15.3 \mathrm{~mL} \mathrm{CO}_{2} \mathrm{~kg}^{-1}$ $\mathrm{h}^{-1}$, respectively. Fruit treated with 20,60 or $90 \%$ of $\mathrm{O}_{2}$ had similar respiration rates $\left(21 \mathrm{~mL} \mathrm{CO}_{2} \mathrm{~kg}^{-1} \mathrm{~h}^{-1}\right)$, which were significantly higher than fruit treated with lower $\mathrm{O}_{2}$ concentrations. Acetaldehyde and ethanol levels did not increase during storage. Pulp firmness did not vary among treatments. Strawberries subjected to $60 \%$ of $\mathrm{O}_{2}$ maintained adequate levels of titratable acidity and ascorbic acid during the storage; however ascorbic acid decreased in all other treatments. Strawberry external color varied slightly depending on $\mathrm{O}_{2}$ concentration; however, these differences were not visually perceptible. 'Oso Grande' strawberries stored at $10{ }^{\circ} \mathrm{C}$ under controlled atmosphere with 60 and $90 \%$ of $\mathrm{O}_{2}$ preserved the appearance and reduced decay, when compared to the other treatments.
\end{abstract}

Index terms: Controlled Atmosphere, Oxygen Control, Postharvest, Fragaria x ananassa.

\footnotetext{
1(Trabalho 058-11). Recebido em: 12-01-2011. Aceito para publicação em: 03-10-2011. Financiamento e apoio FAPESP ${ }^{2}$ Aluno do Curso de Pós-Graduação em Fitotecnia da ESALQ-USP, Bolsista de doutorado FAPESP. E-mail: luiscarloscunha@hotmail.com ${ }^{3}$ Professores do Dept ${ }^{\circ}$. de Produção Vegetal da Universidade de São Paulo, Escola Superior de Agricultura "Luiz de Queiroz", ESALQ-USP. Av.: Pádua Dias, nº.11, Caixa Postal 9. CEP 13418-900 Piracicaba - SP, Brasil. E-mails: jacomino@esalq.usp.br; jascarpa@esalq.usp.br

${ }^{4}$ Aluno do Curso de Pós-Graduação em Fitotecnia da ESALQ-USP. E-mail: mjtrevis@esalq.usp.br
} 


\section{INTRODUÇÃO}

O morango tem uma curta vida útil, devido à sua elevada atividade metabólica e à suscetibilidade a doenças, principalmente as causadas por fungos (MALGARIM et al., 2006).

$\mathrm{O}$ uso de baixa concentração de $\mathrm{O}_{2}$ (1$5 \%)$ e altas concentrações de $\mathrm{CO}_{2}(10-20 \%)$, em combinação com a refrigeração, são propostas de condições de armazenamento ideal para algumas hortaliças e frutas (VAN DER STEEN et al., 2002). Entretanto, níveis baixos de $\mathrm{O}_{2}$ levam os frutos a respirarem anaerobicamente, resultando na formação de acetaldeído e etanol, e consequentemente modificando o sabor e escurecendo os tecidos dos frutos (SHAMAILA et al., 1992; PÉREZ et al., 1996).

Chitarra e Chitarra (2005) relataram que morangos submetidos à atmosfera com $10 \%$ de $\mathrm{O}_{2}$ e $20 \%$ de $\mathrm{CO}_{2}$ associado a temperaturas de $0-5^{\circ} \mathrm{C}$, conservam-se por até 10 dias. Calegaro et al. (2002) verificaram que atmosfera modificada ativa com concentrações iniciais de $3 \% \mathrm{O}_{2}+10 \% \mathrm{CO}_{2}$ ou $5 \%$ $\mathrm{O}_{2}+15 \% \mathrm{CO}_{2}$, na conservação de morangos 'Oso Grande' armazenados a $0{ }^{\circ} \mathrm{C}$, implicou manutenção da firmeza, da coloração e dos teores de açúcares totais e ácido ascórbico.

Baixas concentrações de $\mathrm{O}_{2}$, com ou sem combinações com altas concentrações de $\mathrm{CO}_{2}$, também podem levar a efeitos benéficos na vida póscolheita de morango, com redução de deterioração e podridões, aumentando o período de conservação (SHAMAILA et al., 1992; VAN DER STEEN et al., 2002).

Holcroft e Kader (1999) observaram que morangos 'Selva', quando armazenados em atmosfera com 2 e $0,5 \%$ de $\mathrm{O}_{2}$ a $5^{\circ} \mathrm{C}$, tiveram o amolecimento e a senescência retardados, quando comparados com frutos armazenados sob $20 \%$ de $\mathrm{O}_{2}$. Estes autores também relataram que atmosferas com 2 e $20 \%$ de $_{2}$ conservaram os frutos de maneira semelhante quanto à cor, concentração de antocianinas e metabolismo dos ácidos orgânicos.

Concentrações de oxigênio superiores a $21 \%$ podem influenciar na fisiologia pós-colheita e na manutenção da qualidade de produtos hortícolas frescos, direta ou indiretamente, através de alterações na produção de $\mathrm{CO}_{2}$ e de $\mathrm{C}_{2} \mathrm{H}_{4}$. O limite do teor de $\mathrm{O}_{2}$ na atmosfera de conservação pode variar, entre espécies e dentro da mesma espécie, dependendo do seu estádio de desenvolvimento (KADER; BENYEHOSHUA, 2000).

Morangos acondicionados em atmosfera com 40; 90 e $100 \%$ de $\mathrm{O}_{2}$ apresentaram baixa ocorrência de doenças, após 14 dias a $5^{\circ} \mathrm{C}$ (WSZELAKI; MITCHAM, 2000). Morango da cv. Chandler armazenado em atmosfera com $100 \%$ de $\mathrm{O}_{2}$ manteve comercializável por 14 dias, e concentrações de 40; $50 ; 80$ e $100 \%$ de $\mathrm{O}_{2}$ levaram à menor produção de compostos voláteis, como acetaldeído e etanol, quando comparados aos frutos em ambiente com $20 \%$ de $\mathrm{O}_{2}$ (AYALA-ZAVALA et al., 2007).

Zheng et al. (2007) demonstraram que morango 'Allstar', armazenados a $5^{\circ} \mathrm{C}$ em ambiente com 21 (controle); 40; 60; 80 e 100\% de $\mathrm{O}_{2}$ tiveram redução na incidência de doenças com o aumento na concentração de $\mathrm{O}_{2}$, sem a ocorrência de perdas de açúcares e ácidos, além da manutenção da coloração.

Ao armazenar morangos em atmosferas com 21 (controle); 40; 60; 80 e $100 \%$ de $\mathrm{O}_{2}$, Zheng et al. (2008) reafirmaram a observação anterior, ou seja, as mesmas reduziram a incidência de doenças sem alterar a coloração. Os frutos submetidos à concentração de $40 \%$ de $\mathrm{O}_{2}$ apresentaram maiores teores de sólidos solúveis que os acondicionados com $60 \%$ de $\mathrm{O}_{2}$.

Neste trabalho, objetivou-se avaliar o efeito de diferentes concentrações de oxigênio na qualidade pós-colheita de morangos cv. Oso Grande, a $10^{\circ} \mathrm{C}$.

\section{MATERIAL E MÉTODOS}

Morangos da cultivar Oso Grande foram colhidos em pomar comercial no município de Valinhos-SP (Latitude $22^{\circ} 58^{\prime}$ sul e Longitude $16^{\circ}$ $59^{\prime}$ oeste), nas primeiras horas do dia, com 50-75\% da superfície de cor vermelho-brilhante, conforme recomendação de Flores-Cantillano (2005). Após a colheita, os frutos foram cuidadosamente transportados para o Laboratório de Pós-Colheita de Produtos Hortícolas, do Departamento de Produção Vegetal da Escola Superior de Agricultura "Luiz de Queiroz" - USP, Piracicaba-SP. Os morangos foram criteriosamente selecionados, com a retirada dos frutos com podridão, ferimentos ou coloração inadequada. Após a homogeneização do lote, os morangos foram acondicionados em câmara frigorifica a $10^{\circ} \mathrm{C}$ para a retirada do calor de campo. A aplicação dos tratamentos teve início quando a temperatura da polpa atingiu aproximadamente $12^{\circ} \mathrm{C}$.

Os morangos selecionados e pré-refrigerados foram armazenados em minicâmaras herméticas, com capacidade de acondicionamento de aproximadamente 1,2 kg de morango, em camada única. As misturas gasosas foram umidificadas e injetadas na parte inferior da minicâmara (entrada), com saída na parte superior e oposta à entrada, em fluxo contínuo de $150 \mathrm{~mL} \mathrm{~min}^{-1}$. 
$\mathrm{O}$ equipamento utilizado para estabelecer e controlar a atmosfera foi o fluxcentro ("Flowboard") descrito por Calbo (1989), com modificação no regulador de pressão, utilizando-se de uma válvula diferencial, utilizada em botijão de gás GLP doméstico, para regular a pressão do equipamento sem perda de gás, como acontece quando se usa um barostato (CERQUEIRA et al., 2009).

Neste experimento, foram testadas cinco misturas gasosas (tratamentos) com as seguintes concentrações de oxigênio: $1 ; 3 ; 20 ; 60$ e $90 \%$. O tratamento com $20 \%$ foi considerado como o tratamento-controle. As misturas foram aferidas diariamente, usando-se um analisador de gases da marca Dansensor, modelo Checkmate 9001.

Os morangos foram armazenados durante 10 dias em câmara a $10 \pm 1{ }^{\circ} \mathrm{C}$. A umidade relativa no interior das minicâmaras foi mantida a $95 \pm 2 \%$ UR, e as avaliações foram realizadas a cada 2 dias para as variáveis descritas a seguir.

A aparência foi avaliada segundo uma escala de notas, onde: 3 = ótimo (sem sintomas de doença; túrgido; com cor característica); 2 = bom (sem sintomas de doença; com cor característica; sem turgidez); 1 = ruim (sem sintomas de doença; sem cor característica; sem turgidez); e $0=$ péssimo (com sintomas de doença). As notas foram atribuídas para o conjunto de frutos contidos em 3 minicâmaras. Morangos com nota 1 foram considerados impróprios para a comercialização.

A incidência de doença foi quantificada visualmente, avaliando-se 110 frutos por tratamento. Foram considerados doentes os frutos que apresentavam lesões características, com dimensão mínima de $25 \mathrm{~mm}^{2}$. Os resultados foram expressos em porcentagem de frutos afetados.

A firmeza da polpa foi determinada com penetrômetro digital marca Tr-Turoni, Sammar 53200 diretamente na lateral dos frutos com ponteira de $6 \mathrm{~mm}$, e os resultados, expressos em Newton $(\mathrm{N})$.

A coloração externa foi determinada nos dois lados de cada fruto, com colorímetro Minolta, modelo CR-300, e os resultados foram obtidos e expressos em luminosidade, ângulo de cor e cromaticidade, de acordo com McGuire (1992).

Os teores de acidez total titulável e sólidos solúveis totais foram determinados de acordo com AOAC (1997), e o de ácido ascórbico, de acordo com Strocker e Henning (1967). Para estas análises, utilizou-se polpa homogeneizada de 30 frutos.

A atividade respiratória foi determinada utilizando-se de 4 repetições, sendo considerada como repetição uma minicâmara com aproximadamente $1,2 \mathrm{~kg}$ de morango. Determinou-se a produção de
$\mathrm{CO}_{2}$, pelo sistema aberto. sendo a primeira leitura realizada após 24 horas do início dos tratamentos e posteriormente a cada 2 dias $(1 ; 3 ; 5 ; 7$ e 9 dias). Foram coletadas amostras de $1,0 \mathrm{~mL}$ de gás na entrada e na saída da minicâmara. utilizando-se de seringa modelo Gastight, marca Hamilton de 2,5 mL. Elas foram analisadas em cromatógrafo a gás (Thermofinnigan, modelo GC Trace 2000), com coluna separadora "Porapak N" e detector de ionização de chama (FID). $\mathrm{O}$ gás de arraste foi o nitrogênio a um fluxo de $39,1 \mathrm{~mL} \mathrm{min.} .^{-1}$. As temperaturas mantidas no aparelho foram de $100^{\circ} \mathrm{C}$ para a coluna, $100^{\circ} \mathrm{C}$ no injetor, $250^{\circ} \mathrm{C}$ no detector e $350^{\circ} \mathrm{C}$ no metanador. A produção de $\mathrm{CO}_{2}$ foi calculada através da equação descrita por Kays (1991) e expressa em mL CO $\mathrm{kg}^{-1} \mathrm{~h}^{-1}$.

No preparo das amostras para quantificar os teores de acetaldeído e etanol, amostras de $1 \mathrm{~g}$ de polpa triturada foram seladas em frascos de 40 $\mathrm{mL}$, os quais foram lacrados e mantidos a $-12^{\circ} \mathrm{C}$ até o momento da análise. Na mesma amostra, foram quantificados os teores de acetaldeído e etanol. A curva-padrão de acetaldeído foi preparada pesandose $0,085 \mathrm{~g}$ de acetaldeído e completando-se o volume para $400 \mathrm{~mL}$ com água deionizada gelada. Desta solução, pipetaram-se $1,0 \mathrm{~mL} ; 10,0 \mathrm{~mL}$ e $20,0 \mathrm{~mL}$ para balões volumétricos de $100 \mathrm{~mL}$, cujo volume foi completado com água deionizada gelada. Esta solução foi homogeneizada e transferida para frascos herméticos. A curva-padrão de etanol foi preparada pesando-se $0,01 \mathrm{~g} ; 0,14 \mathrm{~g}$ e $0,81 \mathrm{~g}$ de etanol para balões volumétricos de $200 \mathrm{~mL}$, cujo volume foi completado com água deionizada gelada. Esta solução foi homogeneizada e transferida para frascos herméticos. A determinação dos dois compostos deu-se transferindo $1,0 \mathrm{~mL}$ de cada solução-padrão para frascos de $40 \mathrm{~mL}$, onde foram lacrados e mantidos em banho-maria a $50^{\circ} \mathrm{C}$ por 30 minutos. Coletou-se 1,0 mL de ar do espaço livre (head space) do frasco, que foi analisado em cromatógrafo a gás. Este procedimento também foi o mesmo adotado para as amostras, após o descongelamento por 1 hora em temperatura ambiente. Os resultados foram expressos em mg de acetaldeído ou etanol por 100 $\mathrm{g}$ de material vegetal.

O experimento foi montado através do delineamento inteiramente casualizado, em esquema fatorial $6 \times 5$. Os fatores foram constituídos pelos períodos de armazenamento $(0 ; 2 ; 4 ; 6 ; 8$ e 10 dias $)$ e pelas atmosferas de armazenamento $(1 ; 3 ; 20 ; 60$ e $90 \%$ de $\mathrm{O}_{2}$ ).

Para as variáveis de qualidade química (teores de acidez total titulável, ácido ascórbico e sólidos solúveis totais), foram utilizadas quatro repetições, com $300 \mathrm{~g}$ de morango em cada dia de análise. Para a 
firmeza e a coloração, foram utilizadas 20 repetições, sendo constituídas de um fruto cada.

Os dados foram submetidos à análise de variância, e as médias foram submetidas à análise de regressão polinomial. Os teores de acetaldeído e etanol e produção de $\mathrm{CO}_{2}$ foram avaliados pelo erro-padrão, em que as diferenças entre as médias de dois tratamentos foram maiores que a soma de dois erros-padrão, foram consideradas significativas (SHAMAILA et al., 1992).

\section{RESULTADOS E DISCUSSÃO}

As atmosferas mais ricas em $\mathrm{O}_{2}$ resultaram em melhor qualidade dos frutos, o que é constatado pelas notas superiores de aparência e menor ocorrência de doenças (Tabela 1). O tratamento com $90 \%$ de $\mathrm{O}_{2}$ proporcionou aos morangos aparência entre ótima e boa, com manutenção da turgidez, coloração semelhante aos frutos recém-colhidos e apenas 3\% de incidência de doenças, seguido pelos frutos, acondicionado com $60 \%$ de $\mathrm{O}_{2}$, os quais apresentaram qualidade visual boa, pequena redução no brilho e $6 \%$ de podridões, no décimo dia de armazenamento.

As maiores porcentagens de doenças e piores notas de aparência foram observadas nos tratamentos com 20;3 e 1\% de $\mathrm{O}_{2}$, respectivamente, que apresentaram sintomas de podridão já no sexto dia de armazenamento. Estes tratamentos não diferiram entre si, indicando que baixas concentrações de $\mathrm{O}_{2}$ atmosférico (1 e 3\%) não apresentam resultado satisfatório na redução de doenças quando comparadas a concentração atmosférica ambiente $\left(20 \%\right.$ de $\left.\mathrm{O}_{2}\right)$.

Zheng et al. (2008) relataram resultados semelhantes quando armazenaram morangos em atmosferas com 60; 80 e $100 \%$ de $\mathrm{O}_{2}$, a $5^{\circ} \mathrm{C}$, os quais apresentaram baixa incidência de frutos doentes, ou seja, 13,$5 ; 11,2$ e $8,3 \%$, respectivamente, enquanto os tratados com composição semelhante da atmosfera natural $\left(20 \%\right.$ de $\mathrm{O}_{2}+0,03 \%$ de $\left.\mathrm{CO}_{2}\right)$ apresentavam $27,7 \%$ de frutos doentes, no décimo quarto dia. Morangos 'Selva' armazenados em atmosfera com 2 e $0,5 \%$ de $\mathrm{O}_{2}$, a $5{ }^{\circ} \mathrm{C}$, apresentaram sintomas de Botrytis apenas no quinto dia de armazenamento, com menor intensidade que o tratamento com 20 $\%$ de $\mathrm{O}_{2}$ (HOLCROFT; KADER, 1999).

O mecanismo pelo qual atmosferas com alta concentração de $\mathrm{O}_{2}$ diminuem o desenvolvimento de doenças e ajudam na conservação dos vegetais ainda não foi elucidado. Uma hipótese é que a atmosfera com alta concentração de oxigênio induz o mecanismo de defesa do vegetal, aumentando sua resistência a doenças (ZHENG et al., 2008), como acontece com a resistência induzida para Alternaria alternata em manga submetida a tratamento com dióxido de carbono (PRUSKY et al., 1993). Neste trabalho, observou-se também que atmosferas com altas concentrações de oxigênio diminuíram a incidência de doenças e aumentaram a conservação pós-colheita dos morangos, o que não foi observado naqueles armazenados sob baixas concentrações de oxigênio.

Os morangos tratados com 20; 60 ou $90 \%$ de $\mathrm{O}_{2}$ apresentaram atividade respiratória semelhante (entre 21,2 e 22,7 mL CO $\mathrm{kg}^{-1} \mathrm{~h}^{-1}$ ). Os frutos mantidos em atmosfera com 1 e $3 \%$ de $\mathrm{O}_{2}$ apresentaram produção de $\mathrm{CO}_{2}$ menor que os demais tratamentos, com valores de 11,3 e $15,3 \mathrm{~mL} \mathrm{CO}_{2} \mathrm{~kg}^{-1} \mathrm{~h}^{-1}$, respectivamente (Figura 1). O efeito da baixa concentração de $\mathrm{O}_{2}$ na atividade respiratória foi observado já na primeira avaliação, 24 horas após o estabelecimento da atmosfera controlada, e acentuou-se até o terceiro dia. As atividades respiratórias dos morangos armazenados a 1 e $3 \%$ de $\mathrm{O}_{2}$ foram $45,2 \%$ e $32,4 \%$ menores que o controle, respectivamente.

A redução do oxigênio na atmosfera de armazenamento gera respostas do metabolismo primário e secundário dos vegetais. Entre estas respostas metabólicas, está a redução na atividade respiratória, devido à dificuldade na captação de oxigênio, o que pode afetar o metabolismo do vegetal, com redução no consumo de açúcares solúveis, na síntese e na percepção ao etileno (CHITARRA; CHITARRA, 2005).

As respostas metabólicas dos vegetais acondicionados em altas concentrações de oxigênio são questionáveis, pois ainda há poucos estudos, e estes apresentam diversidade de resultados. Escalona et al. (2006) não encontraram diferenças na produção de $\mathrm{CO}_{2}$ em alface minimamente processada armazenada sob atmosferas com 75 e $20 \%$ de $\mathrm{O}_{2}$, a $1{ }^{\circ} \mathrm{C}$. Wszelaki e Mitcham (2000) estudaram o armazenamento de morango 'Camarosa' a $5^{\circ} \mathrm{C}$, sob atmosferas com 40;60;80; 90 e $100 \%$ de $\mathrm{O}_{2}$ e observaram que essas condições reduziram a atividade respiratória nos três primeiros dias, porém ao final do armazemento apresentaram atividade respiratória maior que os frutos do controle $(20 \%$ de $\mathrm{O}_{2}$ ). Estes autores relataram que as atmosferas com alta concentração de $\mathrm{O}_{2}$ causaram estresse ao morango 'Camarosa'.

As taxas respiratórias encontradas neste trabalho indicam que morangos 'Oso Grande' toleram atmosferas com altos níveis de oxigênio, favorecendo a manutenção da aparência e reduzindo a incidência de doenças. A tolerância dos vegetais aos teores de 
$\mathrm{O}_{2}$ pode variar com a espécie, variedade e o estádio de maturação (KADER; BEN-YEHOSUA, 2000), o que pode explicar as diferenças entre os resultados relatados na literatura.

As concentrações de acetaldeído e etanol apresentaram aumento depois do quarto dia de armazenamento, para os morangos armazenados com 1 e $3 \%$ de $\mathrm{O}_{2}$, sendo que as maiores concentrações foram observadas no final do armazenamento. Os teores de etanol nos frutos armazenados com $1 \mathrm{e}$ $3 \%$ de $\mathrm{O}_{2}$, no final do período de armazenamento, foram de 13,1 e de $12,9 \mathrm{mg} 100 \mathrm{~g}^{-1}$, enquanto as concentrações de acetaldeído foram de 1,4 e de $1,3 \mathrm{mg} 100 \mathrm{~g}^{-1}$, respectivamente (Figura 2). Estas concentrações não causaram odor desagradável aos frutos.

Os morangos acondicionados com 60 e $90 \%$ de $\mathrm{O}_{2}$ apresentaram produção de acetaldeído e de etanol semelhante aos frutos armazenados com $20 \%$ de $\mathrm{O}_{2}$ (Figura 2). Não se observaram as vantagens teóricas de atmosfera com alto oxigênio em termos de evitar a formação desses compostos (DAY, 1996; AYALA-ZAVALA et al., 2007). Especula-se que esta vantagem possibilitaria associação entre altas concentrações de $\mathrm{O}_{2}$ e de $\mathrm{CO}_{2}$, somando-se os beneficios dos dois gases e proporcionando maior tempo de conservação, sem os efeitos prejudiciais do processo fermentativo (PÉREZ; SANZ, 2001).

O acúmulo de acetaldeído, etanol e acetato de etila é originário da respiração anaeróbica e são os principais causadores dos odores desagradáveis em vegetais. Normalmente, a respiração anaeróbica é induzida quando os morangos são armazenados em baixas concentrações de $\mathrm{O}_{2}$ e/ou altas concentrações de $\mathrm{CO}_{2}$ (SHAMAILA et al., 1992; PÉREZ et al., 1996). Os resultados indicam que morangos 'Oso Grande' não apresentam acúmulo prejudicial de substâncias oriundas da respiração anaeróbica, quando armazenados sob atmosferas com 1 e $3 \%$ de $\mathrm{O}_{2}$, na ausência de $\mathrm{CO}_{2}$.Não foi observada diferença significativa entre os tratamentos para a firmeza da polpa. Ocorreu apenas redução linear durante o armazenamento, o que, segundo Chitarra e Chitarra (2005), é devido às mudanças nas estruturas da parede celular, com decomposição de pectinas e celulose, promovendo diminuição nas forças de coesão entre as células. A firmeza dos frutos, neste experimento, foi de aproximadamente $9 \mathrm{~N}$ no momento da colheita e 7,5 $\mathrm{N}$ no décimo dia de armazenamento (Figura $3 \mathrm{~A}$ ).

Estes resultados obtidos vão ao encontro daqueles obtidos por Wszelaki e Mitcham (2000), que estudaram morangos 'Camarosa' armazenados a $5{ }^{\circ} \mathrm{C}$ sob atmosferas com 40; 60; 80; 90 e $100 \%$ de $\mathrm{O}_{2}$. Estes autores também não observaram efeito dos tratamentos na firmeza dos frutos armazenados por 14 dias.

Quanto à coloração, os morangos apresentaram tendência de redução nos valores da luminosidade e do ângulo de cor, com leve aumento na cromaticidade, durante o armazenamento (Figura 3). Os morangos armazenados com $20 \%$ de $\mathrm{O}_{2}$ apresentaram a maior redução na luminosidade (de 39 para 33) (Figura 3 B), e no ângulo de cor (de 30, $1^{\circ}$ para $24,7^{\circ}$ ) (Figura $3 \mathrm{C}$ ), durante o armazenamento. Entretanto, Zheng et al. (2008) relataram que, no décimo quarto dia de armazenamento refrigerado $\left(5^{\circ} \mathrm{C}\right)$, morangos 'Fengxiang' não tinham diferenças significativas entre as atmosferas controladas (ar; 40; $60 ; 80$ e $100 \% \mathrm{de}_{2}$ ), para as variáveis luminosidade e ângulo da cor. Os resultados observados nos morangos 'Oso Grande' do tratamento-controle podem ter ocorrido pela temperatura deste trabalho ser o dobro $\left(10^{\circ} \mathrm{C}\right)$ da utilizada por Zheng et al. (2008), o que proporcionou maior velocidade na atividade metabólica e, consequentemente, avanço na senescência, acarretando mudanças na coloração.

As atmosferas de armazenamento com 1; 3 e $20 \%$ de oxigênio proporcionaram aos frutos aumento linear na cromaticidade, passando de 28,2 para 31-34 de cromaticidade (Figura 3 D). Em morangos 'Selva', armazenados a $5^{\circ} \mathrm{C}$, sob atmosfera controlada com $0,5 \%$ de $\mathrm{O}_{2}$,observaram-se leve aumento na cromaticidade e pequena redução nos acondicionados com $2 \%$ de $\mathrm{O}_{2}$ e com atmosfera ambiente (HOLCROFT; KADER, 1999).

Apesar de os parâmetros da coloração apresentarem diferenças estatísticas entre os tratamentos, estas diferenças não foram notadas visualmente, cabendo ressaltar que os frutos acondicionados com $20 \%$ de $\mathrm{O}_{2}$ apresentavam menor brilho que os frutos dos demais tratamentos. Outros trabalhos também indicaram que a alta concentração de oxigênio na atmosfera de armazenamento não provocou grandes alterações na coloração externa de morangos (PÉREZ; SANS, 2001; WSZELAKI; MITCHAM, 2000; ZHENG et al., 2007).

O teor de sólidos solúveis totais dos morangos apresentou leve redução durante o armazenamento, com maior intensidade naqueles frutos em ambiente com $20 \%$ de $\mathrm{O}_{2}$, que diminuiu em aproximadamente $1^{\circ}$ Brix entre o início do período $\left(7,84^{\circ}\right.$ Brix $)$ e o final do mesmo $\left(6,90^{\circ}\right.$ Brix). No décimo dia, foi observado que os morangos acondicionados com $90 \%$ de $\mathrm{O}_{2}$ apresentaram menor teor de sólidos solúveis totais (dados não mostrados).

A variação no teor de sólidos solúveis totais de morangos armazenados em atmosferas com 20; 60 e $90 \% \mathrm{de}_{2}$ é semelhante à relatado por Zheng et 
al. (2007), quando armazenaram morangos 'Allstar' em ambiente com alto teor de $\mathrm{O}_{2}$, por 14 dias a $5^{\circ} \mathrm{C}$. Entretanto, Zheng et al. (2008) observaram que, no décimo quarto dia de armazenamento refrigerado $\left(5^{\circ} \mathrm{C}\right)$, os morangos 'Fengxiang' mantidos em atmosferas com 80 e $100 \%$ de $\mathrm{O}_{2}$ apresentaram maiores teores de sólidos solúveis que os submetidos a ambiente com ar, 40 ou $60 \%$ de $\mathrm{O}_{2}$.

Estes comportamentos diferentes podem ser explicados pelas diferenças entre as cultivares de morangos utilizadas, uma vez que os teores de sólidos solúveis podem variar entre espécies, cultivares, estádios de maturação e clima (CHITARRA; CHITARRA, 2005).

O teor de acidez total titulável nos morangos armazenados sob baixas concentrações de oxigênio ( $1 \%$ e $3 \%$ ) reduziu do valor inicial médio de $0,80 \%$ para $0,75 \%$ no décimo dia. As atmosferas com pressões parciais de 20;60 e $90 \%$ de $\mathrm{O}_{2}$ proporcionaram aos frutos manutenção dos teores de acidez total titulável, com valores de 0,808 a 0,820 $\mathrm{g}$ de ácido cítrico $100 \mathrm{~g}^{-1}$ (Figura $4 \mathrm{~A}$ ).

Zheng et al. (2007) também observaram que $20 ; 40 ; 60 ; 80$ e $100 \%$ de $\mathrm{O}_{2}$, na atmosfera de armazenamento, não promoveram diferenças no teor de acidez em morangos 'Allstar', mas com leve redução nesse teor após 14 dias, a $5^{\circ} \mathrm{C}$. No entanto,
Holcroft e Kader (1999) observaram que morangos armazenados a $5^{\circ} \mathrm{C}$, sob atmosfera controlada com $0,5 \%$ de $\mathrm{O}_{2}$, apresentaram menor acidez titulável que os acondicionados em ambiente com $2 \%$ de $\mathrm{O}_{2}$ e ar (20\%), após 10 dias de armazenamento.

Os morangos armazenados em ambiente com $60 \%$ de $\mathrm{O}_{2}$ mantiveram seus teores de ácido ascórbico em 57,64 mg ácido ascórbico $100 \mathrm{~g}^{-1}$ durante o período, enquanto os frutos mantidos sob as demais atmosferas apresentaram redução durante o armazenamento. Os frutos armazenados sob $1 \mathrm{e}$ $3 \%$ de $\mathrm{O}_{2}$ apresentaram a maior redução e valores finais de 50,98 e 52,15 mg ácido ascórbico $100 \mathrm{~g}^{-1}$, respectivamente (Figura $4 \mathrm{~B}$ ).

A redução acentuada no teor de ácido ascórbico nos frutos armazenados com baixo oxigênio pode ser explicada pelo fato de que estes frutos podem ter iniciado o processo de respiração anaeróbica, o que pode ser comprovado pelos maiores valores de acetaldeído e etanol (Figura 2). O ácido ascórbico passaria pelo processo fisiológico conhecido por delactonização, que é a transformação deste em ácido 2,3-dicetogulônico, e assim diminuindo sua atividade biológica (CHITARRA; CHITARRA, 2005).

TABELA 1 - Aparência e ocorrência de doenças de morango 'Oso Grande' submetidos à atmosfera controlada com diferentes concentrações de oxigênio, em armazenamento a $10^{\circ} \mathrm{C}$ e $95 \%$ UR

\begin{tabular}{|c|c|c|c|c|c|}
\hline \multirow{2}{*}{ Dias } & \multicolumn{4}{|c|}{ Aparência } & \multirow[b]{2}{*}{$90 \% \mathrm{O}_{2}$} \\
\hline & $1 \% \mathrm{O}_{2}$ & $3 \% \mathrm{O}_{2}$ & $20 \% \mathrm{O}_{2}$ & $60 \% \mathrm{O}_{2}$ & \\
\hline $\mathbf{0}$ & 3 & 3 & 3 & 3 & 3 \\
\hline 2 & 3 & 3 & 3 & 3 & 3 \\
\hline 4 & 2,75 & 3 & 2,5 & 3 & 3 \\
\hline 6 & 2,5 & 2,25 & 2,25 & 2,75 & 2,75 \\
\hline 8 & 2 & 2 & 1,5 & 2,5 & 2,75 \\
\hline \multirow[t]{2}{*}{10} & 1,25 & 1,5 & 1 & 1,75 & 2,5 \\
\hline & \multicolumn{5}{|c|}{ Ocorrência de doença (\%) } \\
\hline $\mathbf{0}$ & 0 & 0 & 0 & 0 & 0 \\
\hline 2 & 0 & 0 & 0 & 0 & 0 \\
\hline 4 & 0 & 0 & 0 & 0 & 0 \\
\hline 6 & 6,4 & 6,4 & 10 & 0 & 0 \\
\hline 8 & 8,2 & 16,3 & 12,7 & 2,7 & 2,7 \\
\hline 10 & 16,3 & 19,1 & 20,9 & 6,4 & 2,7 \\
\hline
\end{tabular}

Aparência: 3 = ótimo; 2 = bom; 1 = ruim e 0 = péssimo; \% Doença: calculadas pela relação entre o número de frutos com podridões e o número total de frutos avaliados $(\mathrm{n}=110)$. 


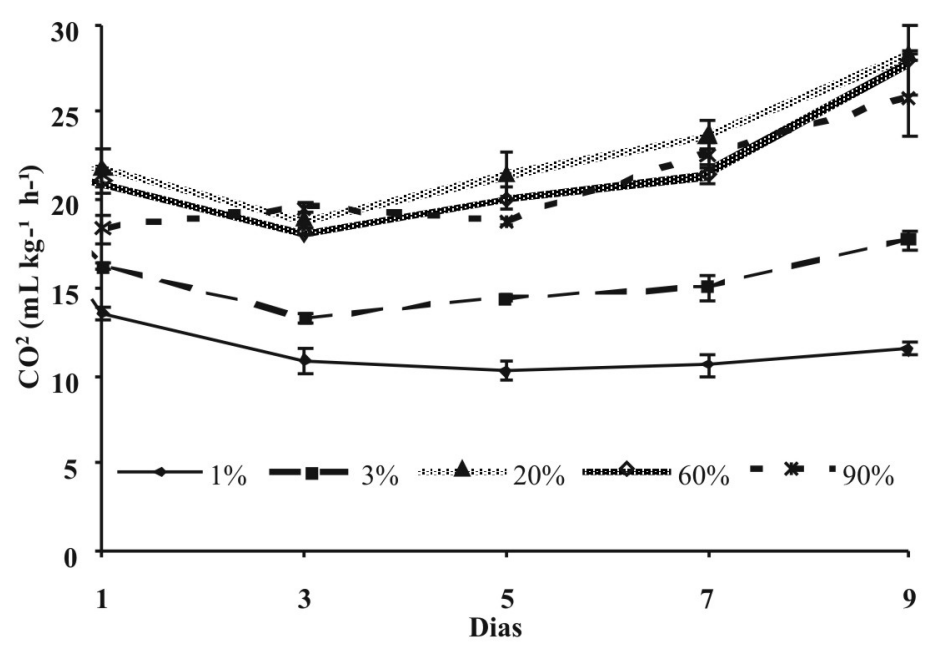

FIGURA 1 - Atividade respiratória de morangos 'Oso Grande' submetidos à atmosfera controlada com diferentes concentrações de oxigênio, em armazenamento a $10^{\circ} \mathrm{C}$ e $95 \%$ UR. As barras verticais indicam o erro-padrão da média $(n=4)$.

A)

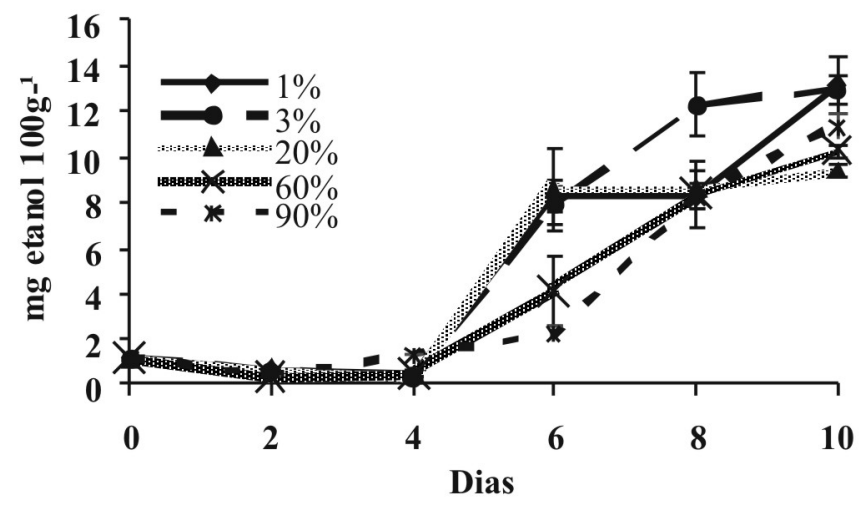

B)

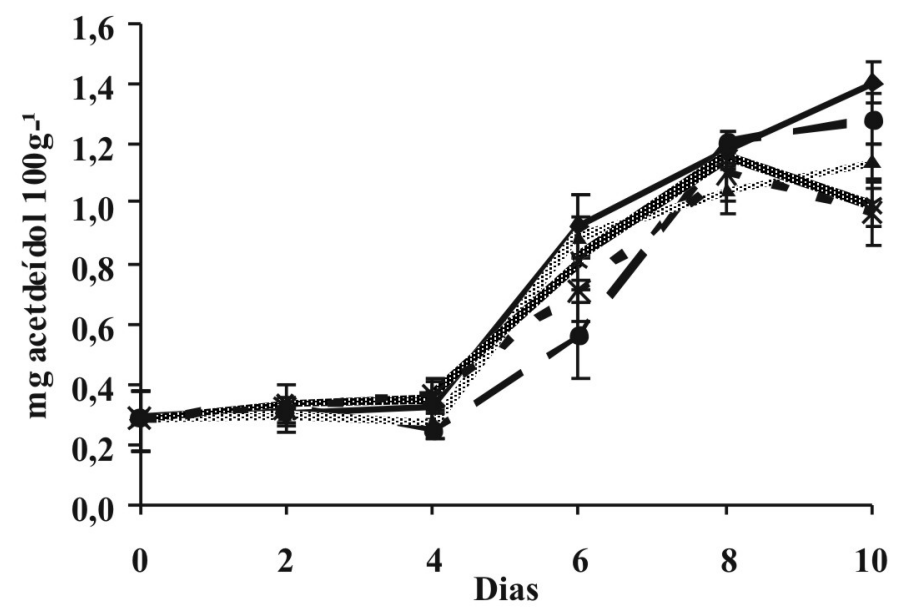

FIGURA 2 - Produção de etanol (A) e acetaldeído (B) nos morangos 'Oso Grande' submetidos à atmosfera controlada com diferentes concentrações de oxigênio, em armazenamento a $10^{\circ} \mathrm{C}$ e $95 \% \mathrm{UR}$. As barras verticais indicam o erro-padrão da média $(n=4)$. 


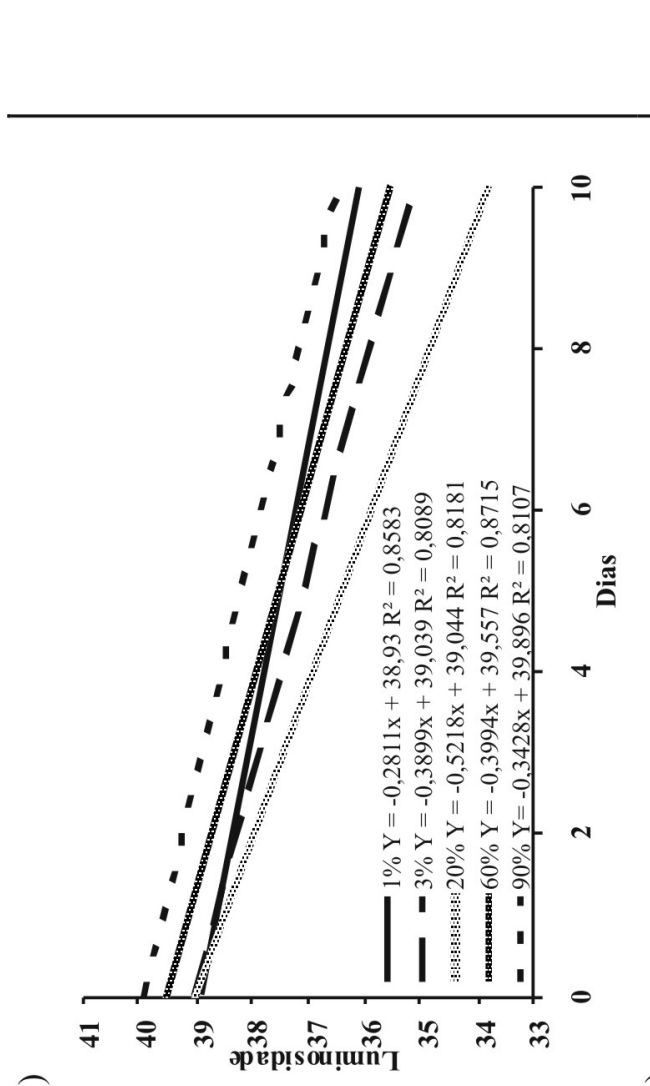

$\widehat{\oplus}$

ลิ
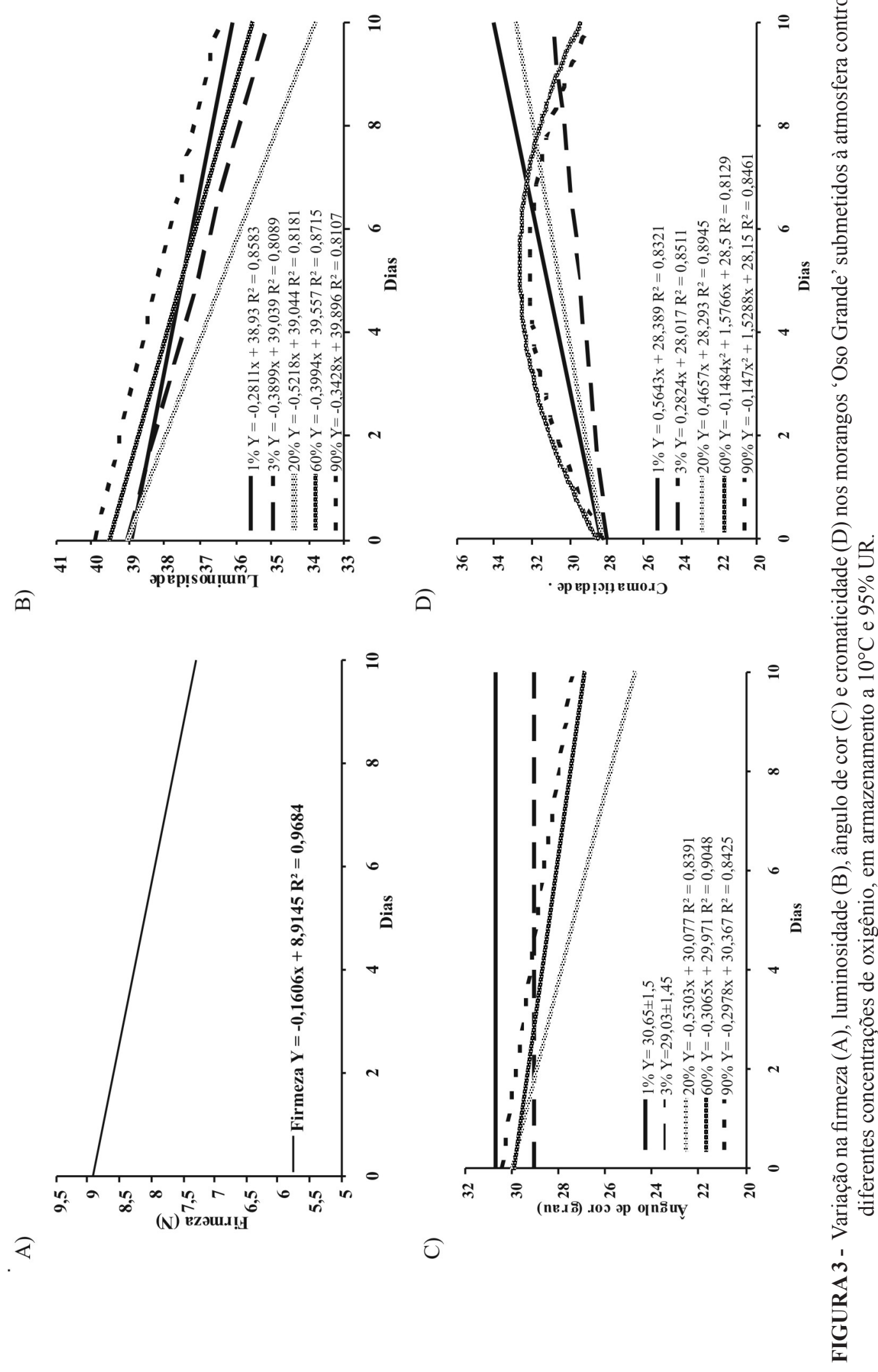
A)

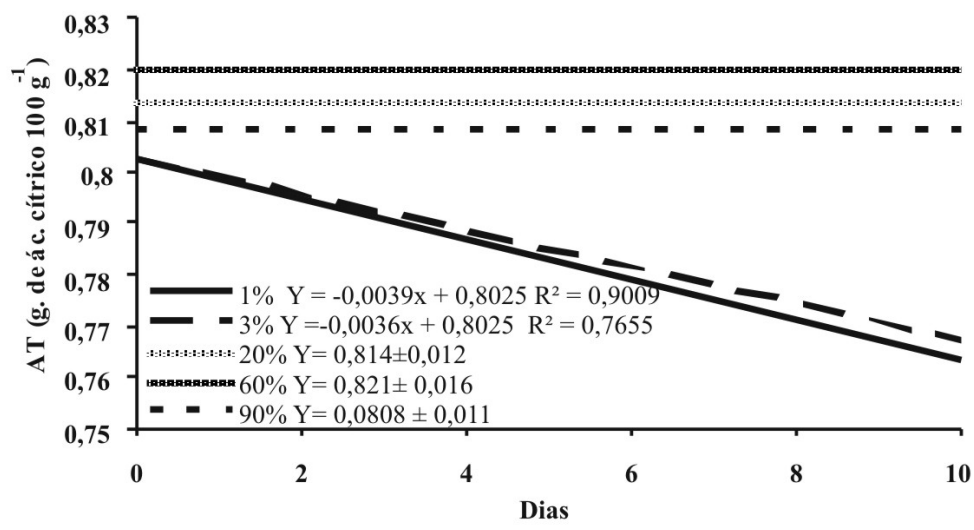

B)

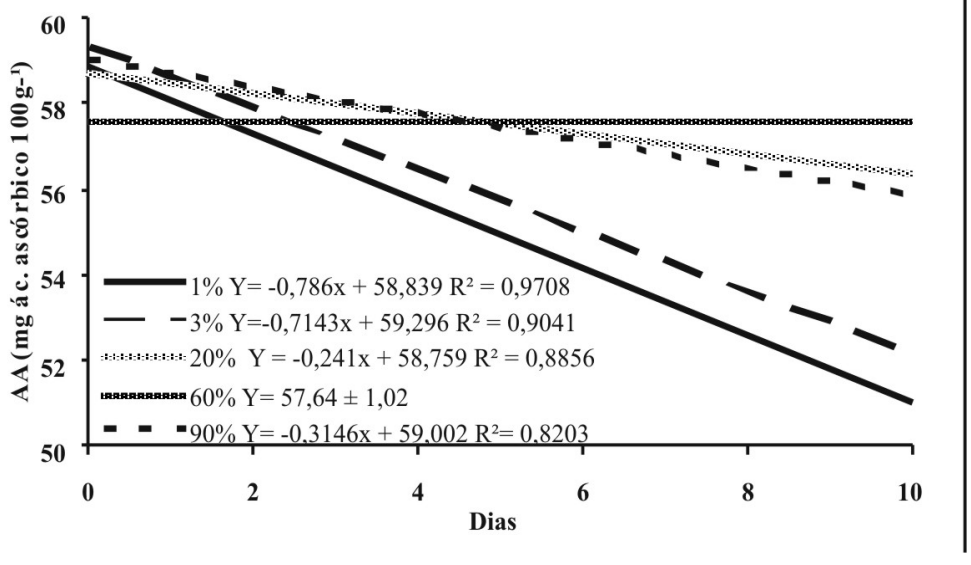

FIGURA 4 - Variação no teor de acidez total titulável (A) e ácido ascórbico (B) de morangos 'Oso Grande' submetidos à atmosfera controlada com diferentes concentrações de oxigênio, em armazenamento a $10^{\circ} \mathrm{C}$ e $95 \%$ UR.

\section{CONCLUSÃO}

1-O armazenamento de morangos 'Oso Grande' a $10^{\circ} \mathrm{C}$ e $95 \%$ UR sob atmosfera controlada com 60 e $90 \%$ de $\mathrm{O}_{2}$ promove a ausência de podridões durante seis dias e a manutenção da aparência dos mesmos até o décimo dia.

2-A ausência de aumento na respiração dos morangos armazenados em ambiente com 60 e $90 \%$ de $\mathrm{O}_{2}$ e a manutenção das qualidades químicas e físicas dos mesmos demonstram que estas atmosferas são mais apropriadas para conservação de morangos 'Oso Grande' que atmosferas com baixas contrações de oxigênio ( 1 e $3 \%$ de $\mathrm{O}_{2}$ ).

\section{REFERÊNCIAS}

A.O.A.C. Official methods of analysis of the Association of Official Analytical Chemists International. 16 ed. Washington: Ed. Patrícia Canniff, 1997. v.2, 850 p.

AYALA-ZAVALA, J.F.; WANG, S.Y.; WANG, C.Y.; GONZÁLES-AGUILAR, G.A. High oxygen treatment increases antioxidant capacity and postharvest life of strawberry fruit. Food Technology and Biotechnology, Croácia, v. 45, n.2, p 166-173, 2007.

CALBO, A.G. Adaptação de um fluxcentro para estudos de trocas gasosas e um método de aferição de capilares. Pesquisa Agropecuária Brasileira, Brasília, v.24, n.6, p.733-739, 1989. 
CALEGARO, J.M.; PEZZI, E.; BENDER, R.J. Utilização de atmosfera modificada na conservação de morangos em pós-colheita. Pesquisa Agropecuária Brasileira, Brasília, v. 37, n. 8, p. 1049-1055, 2002.

CERQUEIRA, T.S.; CUNHA JÚNIOR, L.C.; CALBO, A.G.; JACOMINO, A.P. Flowboard for postharvest gas mixtures applications to fruits and vegetables without waste of gas. In: INTERNATIONAL CONTROLLED AND MODIFIED ATMOSPHERE RESEARCH CONFERENCE, 10., 2009, Antalya. Abstracts... Leuven: ISHS, 2009. p. 56-56.

CHITARRA, M.I.F.; CHITARRA, A.B. Pós-colheita de frutas e hortaliças: fisiologia e manuseio. 2.ed. Lavras: FAEPE, 2005.783p.

DAY, B.P.F. High oxygen modified atmosphere packaging for fresh prepared produce. Postharvest News and Information. Wallingford, v. 7, n.3, p.31-34, 1996.

ESCALONA, V.H.; VERLINDEN, B.E.; GEYSEN, S.; NICOLAII, B.M. Changes in respiration of freshcut butterhead lettuce under controlled atmospheres using low and superatmospheric oxygen conditions with different carbon dioxide levels. Postharvest Biology and Technology, Amsterdam, n.39, n.1, p. 48-55. 2006.

FLORES-CANTILLANO, R.F. Colheita e póscolehita. In: PEREIRA, D.P.; BANDEIRA, D.L.; QUINCOZES, E. da R.F. (Ed.). Sistema de produção do morango. Pelotas: EMBRAPA Clima Temperado, 2005. (Sistema de produção, 5). Disponível em: <http://sistemasdeproducao.cnptia.embrapa.br/ FontesHTML/Morango/SistemaProducaoMorango/ cap12.htm>. Acesso em: 5 fev.2010.

HOLCROFT, D.M.; KADER, A.A. Controlled atmosphere-induced changes em $\mathrm{pH}$ and organic acid metabolim may affect color of stored strawberry fruit. Postharvest Biology and Technology, Amsterdam, v.17, n.1, p.19-32, 1999.

KADER, A.A.; BEN-YEHOSHUA, S. Effects of superatmospheric oxygen levels on postharvest physiology and quality of fresh fruits and vegetables. Postharvest Biology end Technology, Amsterdam, v.20, n.1, p. 1-13, 2000.

KAYS, S.J. Postharvest physiology of perishable plant products. New York: AVI Book, 1991. 532p.

MALGARIM, M.B.; CANTILLANO, R.F.F.; COUTINHO, E.F. Sistemas e condições de colheita e armazenamento na qualidade de morangos cv. Camarosa. Revista Brasileira de Fruticultura, Jaboticabal, v. 28, n. 2, p. 185-189, 2006.
McGUIRE, R.G. Reporting of objective color measurements. HortScience, Alexandria, v.27, n.12, p.1254-1255,1992.

PÉREZ, A.G.; SANZ, C.; OLÍAS, R.; RÍOS, J.J.; OLÍAS, J.M. Evolution of strawberry alcohol acyltransferase during fruit development and storage. Journal Agriculture Food Chemistry, Washington, v. 44, n.2, p.3286-3290, 1996.

PÉREZ, A.G.; ZANZ, C. Effect of hight-oxigen and high-carbon-dioxide atmospheres on strawberry flavor and other quality traits. Journal Food Chemistry, Washington, v.49, n.2, p.2370-2375, 2001.

PRUSKY, D.; KOBILER, H.; ZAUBERMAN, G.; FUCHS, Y. Preharvest conditions and postharvest treatments affecting the incidence of decay in mango fruits during storage. Acta Horticulturae, The Hague, v.341, n.1, p.305-320, 1993.

SHAMAILA, M.M.; POWRIE, W.D.; SKURA,B.J. Sensory evaluation of strawberry fruit stores under modified atmosphere packaging (MAP) by quantitative descriptive analysis. Journal of Food Science, Chicago, v. 57, n.5, p. 1168-1172, 1992.

STROHECKER, R.L.; HENNING, H.M. Analisis de vitaminas: métodos comprobados. Madrid: Paz Montalvo, 1967. 428 p.

VAN DER STEEN, C.; JACXSENS, L.; DEVLIEGHERE, F.; DEBEVERE, J. Combining high oxygenatmospheres with low oxygen modified atmosphere packaging to improve the keeping quality of strawberries and raspberries. Postharvest Biology and Technology, Amsterdam, v. 26, n. 1, p. 49-58, 2002.

WSZELAKI, A.L.; MITCHAM, E.J. Effects of superatmospheric oxygen on strawberry fruit quality and decay. Postharvest Biology and Technology, Amsterdam,v.20,n.2, p.125-133, 2000.

ZHENG, Y.; YANG, Z.; CHEN, X. Effect of high oxygen atmospheres on fruit decay and quality in Chinese bayberries, strawberries and blueberries. Food Control, London, v.19, n.3, p. 470-474, 2008.

ZHENG, Y.; WANG, S.Y.; WANG, C.Y.; ZHENG, $\mathrm{W}$. Changes in strawberry phenolics, anthocyanins, and antioxidant capacity in response to high oxygen treatments. Food Science and Technology London, v. 40, n.1, p. 49-57, 2007. 